Stereotype threat-effects for

Turkish-origin migrants in

Germany: Taking stock of

cumulative research evidence
European Educational Research Journal

$1-25$

(C) The Author(s) 2018

Article reuse guidelines: sagepub.com/journals-permissions DOI: | $0.1|77 /| 474904$ | | 8807539 journals.sagepub.com/home/eer

@SAGE

\title{
Laura Froehlich
}

FernUniversität in Hagen, Germany

\section{Sog Yee Mok}

University of Zurich, Switzerland

\section{Sarah E. Martiny}

UiT, The Arctic University of Norway, Norway

\section{Kay Deaux}

New York University, USA

\begin{abstract}
Turkish-origin migrants on average show lower academic performance than Germans. This achievement gap cannot be fully explained by socio-economic differences between the groups. Negative competence stereotypes about Turkish-origin students predict the causal attributions that German preservice teachers make for migrants' academic underperformance. Specifically, the more strongly preservice teachers endorse negative competence stereotypes, the more likely they are to attribute academic underperformance of Turkish-origin migrants to the migrants themselves and less to the educational system. Stereotype threat theory posits that the activation of stereotypes in test situations can reduce the performance of members of the negatively stereotyped group. Based on this theory, we propose that negative stereotypes provide a social-psychological explanation for the academic underperformance of Turkish-origin migrants compared to Germans. A series of six experiments conducted within a research project funded by the German Ministry of Education and Research investigated stereotype threat effects for Turkishorigin migrants. Two new moderator variables were identified: implicit theory of intelligence and
\end{abstract}


vertical collectivism. A meta-analysis of the six studies showed a small, non-significant mean effect for stereotype threat main effects, but a significant medium-sized mean effect for moderated stereotype threat effects. Limitations and practical implications of stereotype threat effects in educational settings are discussed.

\section{Keywords}

Stereotype threat, Turkish-origin migrants, stereotypes, education, social identity

Children and adolescents living in Germany have heterogeneous ethnic backgrounds. For example, $36 \%$ of elementary-school students have either immigrated to Germany themselves or have parents or grandparents who have immigrated (Statistisches Bundesamt, 2016). Students' ethnic background is one factor that predicts their educational performance: on average, German students show higher performance than students from other ethnic groups. In other words, migrant students are disadvantaged in the German educational system compared to their native peers (e.g. Klieme et al., 2010; Prenzel, 2013; Rauch et al., 2016). Migrants have shown lower performance in various academic domains (e.g. mathematics, science, and reading literacy) across a variety of age groups (e.g. elementary- and secondary-school students). Research has identified several variables related to students' economic and socio-cultural context that explain the performance differences between migrant and non-migrant students. If, for example, students' socio-economic status, their parents' education, and the language spoken within the family are statistically controlled for, the performance differences are considerably reduced or even non-significant (e.g. Mok et al., 2016; Prenzel, 2013; Rauch et al., 2016; Schwippert, Wendt, and Tarelli, 2012; Stanat, Rauch, and Segeritz, 2010; Wendt, Schwippert, and Stubbe, 2016). However, the picture is more complex, as the patterns of educational disadvantage are not uniform for all ethnic groups of migrant students. Specifically, for students of Turkish origin the performance differences compared to Germans remain significant even when economic and socio-cultural context variables are statistically controlled for (e.g. Autorengruppe Bildungsberichterstattung, 2016). This means that in contrast to other migrant groups in Germany, some of the causes for the underperformance of Turkish-origin students are still unaccounted for.

Turkish-origin migrants are the largest migrant group in Germany (2.80 million persons in 2016) and constitute $15.1 \%$ of all migrants living in Germany (Statistisches Bundesamt, 2017). Almost half of them (47\%) were actual migrants to Germany, many of whom arrived in Germany as so-called "guest workers" mainly to be employed in the industrial sector during the 1950s to 1970s (Statistisches Bundesamt, 2017). The remaining 53\% were born in Germany as secondgeneration (i.e. parents have migrated) or third-generation migrants (i.e. grandparents have migrated). Turkish-origin migrants are on average younger than the German population without migration background: whereas the mean age of Germans without migration background is 46.9 years $(20.4 \%$ are younger than 26 years), Turkish-origin migrants are on average 33.2 years old (38.9\% are younger than 26 years; Statistisches Bundesamt, 2017). Because of this relatively young demographic, a substantial proportion of Turkish-origin migrants are likely to be enrolled in educational programs. Therefore, young Turkish-origin migrants have a high potential to be integrated into German society via the route of education. Education is a basis for integration in terms of further participation in central societal domains (e.g. economy and the labor market, e.g. De Paola and Brunello, 2016; Die Beauftragte der Bundesregierung für Migration, Flüchtlinge und Integration, 2016). However, Turkish-origin migrants have more difficulties in performing well in 
Germany's academic system than do Germans without migration background or other migrant groups (e.g. Autorengruppe Bildungsberichterstattung, 2016), which can act as a barrier to their societal integration.

In order to overcome the inequalities related to ethnicity in the German educational system, research needs to identify further variables that explain the remaining performance differences between Turkish-origin and German students. In the present work, we focus on a psychological variable, namely stereotypes, that is, how Turkish-origin migrants are viewed in German society. Stereotypes are important in this context because research has shown that stereotypes not only reflect the general social climate within a society, but can also influence group members' academic performance (e.g. Steele and Aronson, 1995). Academic performance is in turn related to migrants' societal and economic integration (e.g. Länderoffene Arbeitsgruppe "Indikatorenentwicklung und Monitoring”, 2017). Therefore, negative stereotypes can create a vicious cycle perpetuating the unfavorable situation for Turkish-origin migrants in Germany in that negative stereotypes predict lower academic performance and thus lower integration, which is in turn related to a more negative view of Turkish-origin migrants by the German majority.

In this manuscript, we will first focus on the socio-cultural climate for Turkish-origin migrants in Germany by reviewing social-psychological research on stereotypes about this group in the educational domain. We will then summarize how stereotypes can reduce the academic performance of negatively stereotyped group members - a phenomenon called stereotype threat (e.g. Steele, 1997) and review studies investigating stereotype threat effects for migrants in the European context. In the next section of the manuscript, we review and meta-analyze evidence showing that stereotype threat can contribute to an explanation of the academic underperformance of Turkishorigin students in the German educational system. The review and meta-analysis is based on six empirical studies that were conducted within a research project funded by the German Federal Ministry of Education and Research (BMBF). In this project, we also identified two new moderator variables of stereotype threat for Turkish-origin migrants: vertical collectivism and implicit theory of intelligence. These variables help to explain individual differences in Turkish-origin students' susceptibility to stereotype threat (i.e. the extent to which their performance is reduced due to the activation of stereotypes). The current research focuses on Turkish-origin adolescents (9th/10th grade), because we consider the influence of stereotype threat most relevant during primary and secondary schooling. Education in these years is the basis for university education, vocational training and participation in the labor market.

\section{Negative stereotypes about Turkish-origin migrants in Germany}

We argue that the perception of Turkish-origin migrants in German society (i.e. the socio-cultural climate) can have important consequences for their educational success and subsequent societal integration. In order to investigate this socio-cultural climate, we focus on stereotypes, which are "beliefs and associations that link a whole group of people with certain traits or characteristics" (Kassin, Fein, and Markus, 2011: 148), and are socially shared in a given context (e.g. the national context of Germany). Stereotypes are a central social-psychological variable to explain academic performance differences between Germans and Turkish-origin migrants. Based on the stereotype content model (Fiske et al., 2002), stereotypes can be described on two basic dimensions: warmth and competence. The warmth dimension reflects the basic question "What is the outgroup's intent toward the ingroup?" and encompasses perceptions of friendliness and likability of a given social group. Outgroups are rated low on warmth if they are perceived to be in competition with the ingroup or if they are perceived to be a threat to the ingroup's resources and values (e.g. Kervyn, Fiske, and Yzerbyt, 2015). The competence dimension reflects the basic question "How capable is 
the outgroup of realizing this intent?" and encompasses perceptions of respect and competence. Outgroups are rated low in competence if they are perceived to have low societal status (e.g. Kervyn et al., 2015). Stereotypical perceptions of different social groups usually vary and can be mapped on the two-dimensional stereotype content space, with each group receiving high or low ratings on either dimension (Cuddy, Fiske, and Glick, 2007). As the socio-cultural climate for different migrant groups usually varies within a given society, stereotypes about migrant groups also vary along warmth and competence (Lee and Fiske, 2006).

In the context of educational performance, the competence dimension is of particular relevance, because it can shape majority members' expectations and attitudes toward migrants, and can also influence migrants' academic achievements. Therefore, we summarize the results of a series of three correlational studies we conducted with German preservice teachers as participants (Froehlich et al., 2016b) to investigate the stereotypes these preservice teachers have about two different migrant groups in Germany: Turkish-origin and Italian-origin migrants. Preservice teachers are students studying to become teachers who already have some teaching experience. Investigating stereotypes among preservice teachers is particularly relevant, because they will teach students from different ethnic backgrounds in the future. Preservice teachers' stereotypes affect how they view different migrant groups and might shape their behavior toward migrant students. We selected the groups of Turkish-origin and Italian-origin migrants because, in the German context, Turkishorigin migrants are stereotyped most negatively, namely as cold and incompetent, whereas Italianorigin migrants show comparably low educational performance but are not stereotyped as negatively (Asbrock, 2010; Froehlich et al., 2016b; Schmid, 2014). Results of the three studies showed that Turkish-origin migrants were stereotyped more negatively than Italian-origin migrants and Germans (Froehlich et al., 2016b). We further investigated how competence stereotypes about the two migrant groups predicted the extent to which German preservice teachers perceived the migrant groups to be responsible for their low academic performance. Results showed that the more negative the competence stereotypes, the more migrants themselves were seen as responsible for their low performance. This relationship was stronger for Turkish-origin than for Italian-origin migrants. Negative competence stereotypes also predicted that participants perceived the educational system as less responsible for migrants' low performance. However, this pattern emerged only for Turkish-origin, but not for Italian-origin migrants. In sum, these results substantiate that the stereotypes German preservice teachers endorse are important for how they perceive the academic situation of different migrant groups. When preservice teachers think that migrants are performing poorly because they lack motivation or ability rather than because they are disadvantaged in the educational system, then they might perceive their own pedagogical opportunities as limited and might be less motivated to support and foster these migrant students. Thus, they might not actively contribute to the educational integration of those migrants but rather perpetuate the ethnic inequalities in the German educational system.

Importantly, results also showed that not all migrant groups with low academic performance were perceived in the same way. Both Italian- and Turkish-origin migrants are perceived to have low status in German society, underperform in the educational system compared to Germans (e.g. Baier et al., 2010; Schmid, 2014), and are stereotyped as incompetent. However, Italian-origin migrants' intent toward Germans is perceived to be more positive and friendly and Italian-origin migrants are consequently stereotyped as higher on warmth than are Turkish-origin migrants (Asbrock, 2010; Froehlich et al., 2016b; Froehlich and Schulte, 2018; Schmid, 2014). These differences in the social perception of the ethnic groups predicted different perceptions of responsibility for the low performance. In general, negative competence stereotypes have various consequences in the educational context: students belonging to negatively stereotyped ethnic groups can be discriminated against (e.g. Whitley and Kite, 2016) by their classmates and teachers, and they can also be hindered from fulfilling their 
academic potential (e.g. Steele and Aronson, 1995). Taken together, the socio-cultural climate for the largest group of migrants in Germany, namely, Turkish-origin migrants, is quite negative, which makes it especially relevant to investigate the consequences of stereotypes for this particular ethnic group. Therefore, we argue that the influence of stereotypes can account for some of the yet unexplained variance in performance differences between Germans and Turkish-origin migrants.

\section{Stereotype threat}

Stereotype threat theory was originally developed to provide a social-psychological account for the achievement gap between African-Americans and white people in the United States (Steele and Aronson, 1995). The theory assumes that group differences in performance are not necessarily based on differences in underlying abilities. Instead, stereotype threat theory proposes that characteristics of the test situation itself can create performance differences, which are in turn related to stereotypes about the intellectual ability of the involved groups (for overviews, see Inzlicht and Schmader, 2012; Spencer, Logel, and Davies, 2016). The activation of stereotypes in test situations can reduce the performance of negatively stereotyped group members (Steele and Aronson, 1995). Specifically, when competence-related stereotypes are activated before a standardized test, members of negatively stereotyped groups show lower performance than when stereotypes are not activated (i.e. stereotype threat effect). The stereotypes are assumed to act as "a threat in the air" to the social identity of stereotyped group members (Steele, 1997). Based on social identity theory (Tajfel and Turner, 1979), the activation of negative stereotypes threatens group members' need to feel good about belonging to the respective group (i.e. a positive social identity associated with the group). The activation of negative stereotypes can be considered as one type of social identity threat (Steele, Spencer, and Aronson, 2002). Individuals need to cope with stereotype threat and are highly motivated to disconfirm the stereotype, which paradoxically leads to reduced test performance (e.g. Schmader, Johns, and Forbes, 2008). Coping strategies to restore a positive social identity include distancing oneself from the negatively stereotyped group (i.e. individual mobility; Tajfel and Turner, 1979, 1986), as well as distancing oneself from the negatively stereotyped domain (e.g. refusing to believe that the stereotype is true; Jones, Ruff, and Paretti, 2013). The mechanisms explaining the resulting performance reduction are complex and can involve increased anxiety, negative thinking, worrying, and mind-wandering (e.g. Pennington et al., 2016). These processes are assumed to reduce the capacity of working memory needed to work on the test, which in turn leads to lower performance (for a meta-analytic overview of mechanisms, see Pennington et al., 2016). The concept of stereotype threat has been extended to various social groups as well as different cognitive domains (Inzlicht and Schmader, 2012; Spencer et al., 2016).

\section{Stereotype threat for migrants in Europe}

Because Turkish-origin migrants are negatively stereotyped, especially in the domain of competence, we hypothesized that stereotype threat provides a further explanation for performance differences between Turkish-origin migrants and Germans in the German educational context, and might thus reduce the variance in ethnic performance differences that is still unaccounted for (e.g. Martiny and Götz, 2011; Schofield and Alexander, 2012; Strasser, 2012). To substantiate this hypothesis, we consider the European context more generally. We summarize empirical evidence that stereotype threat effects contribute to the explanation of performance differences between migrants and non-migrants in different European countries, especially in countries in which the socio-cultural climate for Turkish-origin migrants is assumed to be comparably negative as in Germany (i.e. the Netherlands, Belgium, Austria). 
Two studies with adolescents with Turkish and Moroccan background in Belgium considered the influence of stereotype threat on educational success and academic performance. Baysu, Phalet, and Brown (2011) conducted a study with Turkish-Belgian students and investigated perceived ethnic discrimination as a proxy for stereotype threat in combination with acculturation strategies. Results showed that students who predominantly identified with their ethnic group (i.e. separation) as well as those who predominantly identified with the national group (i.e. assimilation) showed higher educational success when they reported high threat (i.e. frequent discrimination experiences). In contrast, students who identified with both the ethnic and the national group (i.e. dual identity) showed lower educational success when they reported high threat. The authors concluded that dual identity (i.e. integration) is only beneficial in the absence of stereotype threat. However, it should be noted that the study did not contain an experimental design to activate stereotype threat. Another study conducted in Belgium by Baysu et al. (2016) investigated stereotype threat effects for a diverse sample of migrant adolescents predominantly with Turkish and Moroccan backgrounds in ethnically diverse schools. Stereotype threat was activated by making ethnicity salient before (versus after) a performance test. Results of the multilevel analysis in this study showed that the influence of stereotype threat on performance was mediated by disengagement from the performance task. In sum, these two studies show that perceived discrimination and stereotype threat can reduce the educational success and test performance of migrants from Turkish and Moroccan background in Belgium. We therefore argue that stereotype threat effects can also reduce Turkish-origin migrants' academic performance in Germany.

There is first evidence for stereotype threat effects for migrants with diverse ethnic backgrounds in the German-speaking countries of Germany and Austria, which further corroborates our hypothesized stereotype threat effects for Turkish-origin migrants. Weber, Appel, and Kronberger (2015) conducted two experiments in Austria with migrant students of different origins, but predominantly from the Balkans, and investigated stereotype threat in combination with ethnic and national identity strength. Results revealed that higher national identity was related to higher performance under explicit stereotype threat, whereas ethnic identity was unrelated to performance. In a recent study with elementary-school migrant students of different origins in Germany, stereotype threat effects were found in children's verbal learning: When stereotype threat was activated by making salient that the children's first language was non-German, they showed a lower vocabulary increase compared to a control group. Ethnic identity was again unrelated to learning under stereotype threat (Sander et al., 2018).

Finally, a meta-analysis by Appel, Weber, and Kronberger (2015) investigated stereotype threat effects for migrants in Europe and the United States. Overall, results showed a medium-sized stereotype threat effect across 19 independent samples. These studies included Latinos/as in the United States, different migrant groups from African and Arabic countries in France, migrants from diverse backgrounds in Austria and the Netherlands, and migrants from Turkey in Germany (eight studies from Europe, including Studies 1 and 4 from the current meta-analysis). In sum, studies from various European countries showed that negative stereotypes can decrease the performance and learning of migrant students. However, most studies either combined students with very diverse ethnic backgrounds into one sample or did not include a systematic experimental activation of stereotypes. As stereotypes about different migrant groups vary considerably within and across national contexts, it is still an empirical question how strongly the group of Turkish-origin migrants is affected by stereotype threat in the German context. The current review and meta-analysis will focus on the specific group of Turkish-origin migrants in Germany and take stock of the empirical database on stereotype threat currently available for this group and national context. A second aim of this review is to summarize empirical evidence for two newly identified moderator variables of stereotype threat effects for Turkish-origin migrants, which can be important as they attenuate or intensify the experience of stereotype threat for Turkish-origin students. 


\section{Moderators of stereotype threat effects}

Not all individuals experience the performance-reducing consequences of stereotype threat to a similar extent. Research has identified several moderator variables predicting individuals' susceptibility to stereotype threat. These moderator variables predict the degree to which individuals perceive the performance situation and its outcome as important for their social identity and thus for their self-concept, which in turn determines the extent of the performance-reducing effect of stereotype threat (i.e. boundary conditions for stereotype threat effects). Previous studies showed that performance decreases were greater for individuals who were highly identified with the negatively stereotyped group (e.g. Schmader, 2002) and the negatively stereotyped domain (Keller, 2007), who believed the stereotype to be true (Elizaga and Markman, 2008; Schmader, Johns, and Barquissau, 2004), and who had low self-esteem (Rydell and Boucher, 2010) or an internal locus of control (Cadinu et al., 2006). Furthermore, the meta-analysis of Appel et al. (2015) revealed that for migrants in Europe and the United States significant stereotype threat effects emerged in both published and unpublished studies, for different age groups (although effect sizes were larger for adults than for adolescents and children), and for all treatments to activate stereotype threat, as well as for non-verbal and knowledge-based performance tests. When migrant status was determined according to self-identification with an ethnic group, effect sizes were larger compared to when it was determined by demographic variables (Appel et al., 2015). Knowledge about the extent to which members of negatively stereotyped groups are affected by stereotype threat can create pathways to the development of interventions designed to alleviate the consequences of stereotype threat.

However, different target groups of stereotype threat can also be affected by different moderator variables. Based on the hypothesis that stereotype threat effects occur for Turkish-origin migrants in Germany, a next step is the identification of further moderators of stereotype threat for this group. To do so, we aimed at identifying belief/cultural orientation variables that indicate the extent to which Turkish-origin migrants believe the performance situation is important for their social identity, which in turn could predict the degree to which performance is reduced for Turkish-origin migrants under stereotype threat. One such variable is the attitude toward collectivism. Turkish culture can be characterized as more collectivistic than German culture (e.g. Hofstede, Hofstede, and Minkov, 2010; Varnum et al., 2010), which means that belonging to social groups and keeping positive relations with one's fellow group members is important to individuals socialized in the Turkish culture. We believe that this collectivistic cultural orientation of Turkish-origin migrants is important to consider in performance situations because Turkish-origin families have high performance expectations to which Turkish-origin students strive to live upto, especially when negative performance-related stereotypes are activated. Therefore, we investigated two individual-level variables related to Turkish-origin migrants' cultural orientation as further moderators of stereotype threat effects.

Moderator variable:Vertical collectivism. A variable linking Turkish-origin migrants' cultural orientation of collectivism with the perceived importance of the performance situation to their social identity is vertical collectivism (Mok et al., 2017). The Turkish culture endorses values of interpersonal connectedness and social belonging with a strong emphasis on relatedness (e.g. Güngör et al., 2014). This relatedness and behavioral adaptation to group norms is reflected by the concept of vertical collectivism (Singelis et al., 1995). Individuals high in vertical collectivism adhere to group norms and prioritize ingroup members' interests over their own interest (Komarraju and Cokley, 2008). Turkish-origin families expect high achievement motivation and performance from their children (e.g. Phalet and Claeys, 1993; Verkuyten, Thijs, and Canatan, 2001). Thus, Turkish-origin students 
highly endorsing vertical collectivism show high achievement motivation because this is expected by their ingroup members.

One mechanism leading to stereotype threat effects is worrying about one's performance, which occupies the capacity of working memory needed to complete the task (for a review, see Pennington et al., 2016). This worry component of stereotype threat is likely to be exacerbated for individuals high in vertical collectivism, as they might worry that confirming the stereotype by underperforming not only reflects on their individual ability, but also on the ability of their ingroup as a whole. Further, they might be concerned that the negative stereotype implies that they cannot fulfill their ingroup members' high performance expectations. Consequently, we proposed that when negative competence-related stereotypes are activated, Turkish-origin migrants should perform worse, the more strongly they endorse vertical collectivism (Mok et al., 2017).

Moderator variable: Implicit theory of intelligence. Another variable related to Turkish-origin migrants' cultural orientation and the perceived importance of the performance situation for their social identity is one's implicit theory of intelligence. In general, individuals vary in their endorsement of basic conceptions of the nature of intelligence. Some people believe that they have a fixed amount of intelligence that cannot be changed (i.e. an entity theory), whereas others believe that they can increase their intelligence by effort and practice (i.e. an incremental theory; e.g. Dweck, 1999). These lay conceptions of the fixedness or malleability of intelligence have consequences for performance on difficult tasks or after failure. When entity theorists encounter difficulties, their performance is reduced; in contrast, incremental theorists do not experience performance losses in the face of difficulties (e.g. Grant and Dweck, 2001, 2003; Levy, Stroessner, and Dweck, 1998). One mechanism to explain these different reactions to difficulties and related performance differences is that entity theorists endorse performance goals and thus are constantly seeking to verify whether their (fixed) level of intelligence is sufficient to perform successfully on a given task. Difficulties or failure are perceived as indications of lack of ability, which they believe is unchangeable and therefore an undesired outcome. Incremental theorists, however, endorse learning goals and react to difficulties or failure with increased effort and motivation, because they believe that they can thereby increase their ability (e.g. Dweck, Chiu, and Hong, 1995).

We proposed theory of intelligence as a moderator of stereotype threat effects for Turkish-origin migrants (Froehlich et al., 2016a). Competence stereotypes imply that some groups have higher ability than other groups, thus linking social identity to implicit theories of intelligence. Individuals who belong to a group that is negatively stereotyped in the competence domain might infer that because of their group membership their ability is not sufficient to perform well in the respective domain. This should be perceived as more threatening to their social identity by entity theorists than by incremental theorists. In other words, stereotype threat should be exacerbated for entity theorists. The collectivistic cultural orientation of Turkish-origin migrants should make them sensitive to the relationship between negative stereotypes about their group's ability and the performance situation, as their relatedness and subjective importance of group membership is highly important to their identity. Consequently, we proposed that endorsement of an entity theory of intelligence would moderate Turkish-origin migrants' susceptibility to stereotype threat: when negative competence-related stereotypes are activated, Turkish-origin migrants will perform worse the more strongly they endorse an entity theory of intelligence (Froehlich et al., 2016a).

\section{The research project}

Based on the social-psychological evidence for the prevalence of negative competence-related stereotypes about Turkish-origin migrants in Germany as well as evidence for stereotype threat 
effects for various migrant groups in Europe, we investigated whether stereotype threat plays a role in the academic underperformance of Turkish-origin compared to German students. In a research project funded by the German Federal Ministry of Education and Research (BMBF), we conducted a series of six experimental studies in classrooms in order to investigate stereotype threat effects for Turkish-origin migrants (project duration 2012-2015; grant number: 01JC1104). ${ }^{1}$ In the current paper, we take stock of the combined empirical findings on stereotype threat for Turkish-origin adolescents in Germany. Thus, we evaluate how strongly the cumulative evidence supports the following hypotheses: (I) stereotype threat reduces Turkish-origin migrants' test performance; and (II) vertical collectivism and implicit theory of intelligence moderate the extent to which Turkishorigin migrants are susceptible to stereotype threat effects. In a first step, we summarize the empirical evidence from the separate studies, and in a second step, we conduct a meta-analysis to investigate how well the mean effect sizes of the studies support Hypotheses I and II.

\section{Overview of the research design}

We conducted six experiments with 9th- and 10th-grade high-school students on different educational tracks in multicultural urban regions of Germany. Each of the experiments had a two-factorial between-participants design: the first factor was participants' ethnicity (German vs. Turkish migration background). In Study 1, ethnicity was coded according to students' self-identification with ethnic groups, whereas in all other studies demographic information (students' and parents' country of birth) was used. The second factor was experimental condition (stereotype activation vs. no stereotype activation; random assignment of students to conditions in classrooms). Students participated in their classrooms in the presence of an experimenter and a teacher. Prior to working on a standardized test assessing either mathematical or verbal performance, stereotype activation was manipulated in the test instructions. In each study, one of three kinds of experimental manipulations for stereotype activation was used. In the diagnosticity manipulation (e.g. Steele and Aronson, 1995), students either read that the upcoming test was diagnostic of their ability (stereotype activation condition) or that it was a non-diagnostic practice test (control condition). In the fairness manipulation (e.g. Spencer, Steele, and Quinn, 1999) they read that the test had previously produced group differences in performance between Germans and Turkish-origin migrants (stereotype activation condition) or that there were no group differences in performance (control condition). In the identity salience manipulation (Shih, Pittinsky, and Trahan, 2006), either the negatively stereotyped identity (i.e. ethnic group membership) was made salient (stereotype activation condition) or a positive identity (i.e. attendance at private school) was made salient (control condition). Students summarized the instructions (including the experimental manipulation) in writing as a manipulation check (except when the identity salience manipulation was used because identity was made salient by answering identity-related questions) and subsequently worked on the performance test. Finally, they completed a questionnaire assessing psychological variables and demographics, and were fully debriefed. Moderator variables were assessed in separate sessions some time prior to the main sessions. Four of the six studies are published in peer-reviewed journals and the remaining two studies are unpublished. Table 1 presents an overview of the characteristics of the included studies (chronologically ordered according to time of study conduction).

\section{Summary of study results}

\section{Hypothesis I: Stereotype threat effects for Turkish-origin migrants}

Hypothesis I was tested in three experiments (numbered according to Table 1). Study 1 (Martiny et al., 2014a) investigated stereotype threat effects for Turkish-origin migrants in the math domain 
Table I. Overview of characteristics of included studies.

\begin{tabular}{|c|c|c|c|c|c|c|c|}
\hline $\begin{array}{l}\text { Study } \\
\text { (IQB no.) }\end{array}$ & $\begin{array}{l}\text { Reference/ } \\
\text { Authors }\end{array}$ & Status & Sample Size & Manipulation & Domain & Grade level & Moderator \\
\hline I (Ib) & $\begin{array}{l}\text { Martiny } \\
\text { et al., } \\
2014 a\end{array}$ & Published & $\begin{array}{l}N=148 \\
\text { (75 Turkish-origin } \\
\text { migrants, } \\
73 \text { Germans) }\end{array}$ & Fairness & Math & 9th & No \\
\hline $2(2 a / 3 a)$ & $\begin{array}{l}\text { Mok et al., } \\
2014\end{array}$ & Unpublished & $\begin{array}{l}N=200 \\
\text { (79 Turkish-origin } \\
\text { migrants, I2I } \\
\text { Germans) }\end{array}$ & Diagnosticity & Math & 9 th, I0th & No \\
\hline 3 (n.a.) & $\begin{array}{l}\text { Martiny } \\
\text { et al., } \\
2014 \mathrm{~b}\end{array}$ & Unpublished & $\begin{array}{l}N=179 \\
\text { ( } 92 \text { Turkish-origin } \\
\text { migrants, } 87 \\
\text { Germans) }\end{array}$ & Fairness & Verbal & 9 th, I0th & No \\
\hline $4(\mathrm{la})$ & $\begin{array}{l}\text { Froehlich } \\
\text { et al., } \\
2016 \mathrm{a}\end{array}$ & Published & $\begin{array}{l}N=174 \\
\text { (I } 27 \text { Turkish- } \\
\text { origin migrants, } \\
47 \text { Germans) }\end{array}$ & Diagnosticity & Verbal & 9th & $\begin{array}{l}\text { Implicit } \\
\text { theory of } \\
\text { intelligence }\end{array}$ \\
\hline 5 (IcDE) & $\begin{array}{l}\text { Froehlich } \\
\text { et al., } \\
2016 a\end{array}$ & Published & $\begin{array}{l}N=186 \\
\text { (62 Turkish-origin } \\
\text { migrants, } 124 \\
\text { Germans) }\end{array}$ & Diagnosticity & Verbal & 9th & $\begin{array}{l}\text { Implicit } \\
\text { theory of } \\
\text { intelligence }\end{array}$ \\
\hline 6 (n.a.) & $\begin{array}{l}\text { Mok et al., } \\
2017\end{array}$ & Published & $\begin{array}{l}N=94 \\
\text { (94 Turkish-origin } \\
\text { migrants, no } \\
\text { Germans) }\end{array}$ & $\begin{array}{l}\text { Identity } \\
\text { salience }\end{array}$ & Verbal & 9 th, I0th & $\begin{array}{l}\text { Vertical } \\
\text { collectivism }\end{array}$ \\
\hline
\end{tabular}

using a fairness manipulation. The sample consisted of 148 students (75 Turkish-origin migrants, 73 Germans). Age ranged from 13 to 17 years $(M=14.52 ; S D=0.69), 112$ students were female. Results showed an interaction of ethnicity and stereotype activation to predict math performance; $F(1,144)=4.20, p<.040 \eta_{p}^{2}=.03$. In the control condition, the test performance of Turkishorigin migrants and Germans did not differ significantly. However, in the stereotype activation condition, Turkish-origin migrants showed lower performance than Germans; $M_{\text {Diff }}=2.12,95 \%$ $C I=[0.89,3.36], p<.001, d=0.86$. Furthermore, Turkish-origin migrants in the stereotype activation condition also showed lower performance than Turkish-origin migrants in the control condition; $M_{\text {Diff }}=1.19,95 \% C I=[-0.13,2.40], p=.053, d=0.46$. These results reflect a classical stereotype threat effect.

Furthermore, Study 1 investigated two strategies to cope with stereotype threat: increased identification with the ethnic group and decreased belief that the shared stereotype is true. The rationale behind this was that individuals can apply different strategies to cope with stereotype threat and restore a negative social identity (e.g. Tajfel and Turner, 1986). Stereotype threat implies a negative association between the stereotyped group and the performance domain, which threatens negatively stereotyped group members' positive social identity. As a reaction to this threat, individuals can increase their identification with the group in order to reassure and protect their social identity (e.g. Jetten et al., 2016; Tajfel and Turner, 1986). Alternatively, they can refute the socially shared metastereotype (i.e. reject the negative association of the group and the domain; Jones et al., 2013). We investigated whether Turkish-origin migrants used these strategies to cope with stereotype threat. 
Results showed a non-significant trend in the predicted direction: interaction between ethnicity and experimental condition on group identification; $F(1,143)=3.05, p=.083, \eta_{p}^{2}=.02$. The activation of stereotypes did not affect Germans' group identification, but Turkish-origin migrants identified more strongly with their ethnic group after stereotype activation compared to the control condition; $M_{\text {Diff }}=0.86,95 \% C I=[0.14,1.59], p<.001, d=0.55$. Furthermore, there was a twoway interaction on belief in the meta-stereotype; $F(1,138)=4.11, p=.045, \eta_{p}^{2}=.03$. Germans' perception of how most people would evaluate their groups' math ability did not differ between experimental conditions. However, when stereotypes were activated, Turkish-origin migrants perceived that others evaluate Germans' math ability as lower than when no stereotypes were activated; $M_{\text {Diff }}=0.93,95 \% C I=[0.21,1.65], p=.012, d=0.55$. In sum, Study 1 showed a significant stereotype threat effect for Turkish-origin migrants in the math domain, as well as the use of two different coping strategies to manage their social identity under threat.

Study 2 (Mok et al., 2014) investigated stereotype threat in the math domain with a diagnosticity manipulation. The sample consisted of 200 participants (79 Turkish-origin migrants, 121 Germans). Age ranged from 14 to 17 years $(M=14.76 S D=0.81)$, 99 participants were female. Results showed a main effect of ethnicity on test performance (i.e. Turkish-origin migrants showed lower performance than Germans irrespective of stereotype activation; $F(1,196)=7.23, p=.008, \eta_{p}^{2}$ $=.04$, but no stereotype threat effect for Turkish-origin migrants. The internal consistencies of the employed performance measures were in part insufficient, which is a severe limitation of the study.

Study 3 (Martiny et al., 2014b) investigated stereotype threat effects in the verbal domain using the fairness manipulation. The sample consisted of 179 participants (92 Turkish-origin migrants, 87 Germans). Age ranged from 14 to 17 years $(M=15.12, S D=.57), 88$ participants were female. Results again showed no significant interaction of ethnicity and experimental condition on performance (i.e. no stereotype threat effect). Similar to Study 2, the low internal consistency of the performance measure restricted the reliability of results.

In sum, one study (Martiny et al., 2014a) showed that stereotype activation affected Turkishorigin students' math performance and use of strategies to cope with stereotype threat, whereas two further studies were not able to show stereotype threat effects. However, the results of these studies should be interpreted with caution due to psychometric limitations.

\section{Hypothesis II: Moderated stereotype threat effects}

Three additional experiments explored new moderator variables of stereotype threat effects for Turkish-origin migrants in Germany. Studies 4 and 5 (Froehlich et al., 2016a) investigated endorsement of an entity theory of intelligence (i.e. the lay belief that intelligence is fixed) as a moderator of stereotype activation effects. In addition to stereotype threat effects for Turkish-origin migrants (i.e. performance decreases for the negatively stereotyped group), these studies also investigated stereotype lift effects for Germans (i.e. performance increases for the favorably stereotyped group; e.g. Walton and Cohen, 2003). Study 4 consisted of 174 participants (127 Turkish-origin migrants, 47 Germans). Age ranged from 14 to 21 years $(M=14.69, S D=0.82), 69$ participants were female. Study 5 consisted of 186 participants (62 Turkish-origin migrants, 124 Germans). Age ranged from 14 to 18 years $(M=15.21, S D=0.62), 84$ participants were female. Both studies investigated stereotype activation effects in the verbal domain using a diagnosticity manipulation. Results of Study 4 showed that entity theory endorsement moderated stereotype threat effects for Turkish-origin migrants; three-way interaction of entity theory, ethnicity, and condition: $b=-4.02$, $95 \% C I[-7.12,-0.93], \beta=-.61, t(145)=-2.57, S E=1.56, p=.001$. Only when stereotypes were activated did higher entity theory endorsement predict lower performance of Turkish-origin migrants; simple slope: $b=-0.99,95 \% C I[-1.96,-0.02], t(145)=-2.03, S E=0.49, p=.045$. 
Study 5 replicated the moderated stereotype threat effect, but in addition showed that entity theory endorsement positively predicted Germans' performance; three-way interaction: $b=-4.28,95 \%$ $C I[-7.80,-0.76], \beta=-.29, S E=1.78, t(149)=-2.40, p=.018$. When stereotypes were activated, entity theory endorsement predicted lower performance of Turkish-origin migrants; simple slope: $b=-2.11,95 \% C I[-4.24,0.02], t(149)=-1.96, p=.052$; while being associated with higher performance of Germans (i.e. stereotype lift effect; simple slope: $b=1.89,95 \% C I[0.46,3.31]$, $t(149)=2.61, S E=0.72, p=.010)$. Thus, the belief in a fixed view of intelligence predicted the extent to which both members of the negatively stereotyped group and members of the favorably stereotyped group are susceptible to stereotype activation effects.

Lastly, Study 6 (Mok et al., 2017) investigated vertical collectivism as a moderator of stereotype threat effects for Turkish-origin migrants. This study was conducted with 94 Turkish-origin students from two private schools that offered Turkish language classes. Age ranged from 13 to 18 years $(M=15.41, S D=1.03), 48$ participants were female. Study 6 investigated performance in the verbal domain and used the identity salience manipulation. Results showed that vertical collectivism moderated the effects of stereotype activation on Turkish-origin migrants' performance; two-way interaction: $b=-0.66,95 \% C I[-1.24,-0.08], t(89)=-2.30, S E=0.29, p=.024$. Only when negative stereotypes were activated, higher vertical collectivism predicted lower performance; simple slope: $b=0.69,95 \% C I[-1.13,-0.25], t(89)=-3.20, S E=0.22, p=.002$. In addition, Study 6 investigated individual mobility motivation as a further strategy to cope with stereotype threat (Tajfel and Turner, 1979, 1986). Individual mobility describes the tendency to leave the negatively stereotyped group in order to join a higher-status outgroup as a means to restore one's positive social identity (Ellemers, Knippenberg, and Wilke, 1990). In line with vertical collectivism, joining a higher-status (e.g. better performing) outgroup would be a strategy to fulfill the high achievement motivation expected by one's ingroup members. Results supported this reasoning. When negative stereotypes were activated (but not when positive stereotypes were activated), Turkish-origin migrants highly endorsing vertical collectivism were motivated to employ individual mobility strategies (i.e. the desire to represent the outgroup of Germans in a future performance situation and the preference for a higher ratio of Germans than Turkish-origin migrants in a team; two-way interaction: $b=0.81,95 \% C I[0.23,1.39], t(90)=2.81, S E=0.29, p=.006$; simple slope: $b=0.68,95 \% C I[0.24,1.12], t(90)=3.06, S E=0.22, p=.003)$. Thus, Study 6 showed that the cultural orientation of vertical collectivism - along with a high achievement motivation - determined Turkish-origin migrants' susceptibility to stereotype threat effects, as well as individual mobility as an identity management strategy after the activation of negative competence-related stereotypes. Because Appel et al. (2015) showed that stereotype threat effects for migrants were stronger when their self-identification was used compared to their demographic identification, we repeated the analyses of Studies 2-6 with self-identification measures instead of demographic measures and the main results remained statistically significant.

In sum, the current research project has identified two new moderator variables that explain the extent to which Turkish-origin migrants are affected by stereotype threat effects. A belief in the fixedness of intelligence and endorsement of vertical collectivism seem to be especially unfavorable for Turkish-origin students' academic performance in the face of negative stereotypes about their ethnic group's competence.

\section{Meta-analysis}

\section{Aim of the meta-analysis and inclusion criteria}

The aim of the meta-analysis was to investigate whether there is cumulative evidence for (moderated) stereotype threat-effects for Turkish-origin high-school students in Germany. Therefore, the 
inclusion criteria for studies were the following: (1) the studies included an experimental manipulation of stereotype threat, (2) a comparison of Germans with Turkish-origin migrants, (3) a sample of high-school students, as well as (4) they were written/published in English or German language. To investigate whether there were any further studies to be considered for the meta-analysis aside from the studies conducted in the research project described above, we conducted a literature search in March 2018 using all EBSCO Host databases. We used the key words "stereotype threat," "social identity threat," and the German translation "Stereotypenbedrohung" in combination with at least one of the terms "Turk*," "immigra*," "migra*," as well as "Migrationshintergrund" (asterisk as a placeholder for different word endings). In addition, we requested unpublished studies via emailing lists. No further studies fitted the inclusion criteria.

\section{Sample and computation of effect sizes}

The total sample of the six experimental studies consisted of 981 participants (529 Turkish-origin migrants and 452 Germans). The overall mean effect for the stereotype threat effects was analyzed in all six studies, whereas the overall mean effect for the moderated stereotype threat effects was analyzed in a subsample of three studies that included moderator variables in the study design.

To compute the effect sizes of the studies, we used the Comprehensive Meta-Analysis software (Borenstein et al., 2009). We used a random effects model because the participants in the studies attended different school types and were from different federal states in Germany, thus making it likely that the effect sizes varied (Borenstein et al., 2009). To investigate Hypothesis I, we computed the overall mean effect for the stereotype threat effects by using the standardized mean difference (Cohen's $d$; Cohen, 1988) as an effect size measure for performance difference between Turkish-origin migrants in the stereotype activation condition and Turkish-origin migrants in the control condition (Borenstein et al., 2009). To investigate Hypothesis II, we computed the overall mean effect for the moderated stereotype threat effects. In doing so, we followed two steps: first, we entered the $t$-value of the significant simple slope of each moderator variable (i.e. entity theory of intelligence and vertical collectivism) for Turkish-origins migrants in the stereotype activation condition and the sample size of Turkish-origin students of each study in order to compute the coefficient $r$, which indicates a relationship between two variables such as the moderator variable and the stereotype threat manipulation. Second, we transformed the coefficient $r$ of each study into Cohen's $d$ (i.e. standardized mean difference) to make the effect sizes comparable.

\section{Meta-analytic results}

Hypothesis I: Overall mean effect for stereotype threat effects. The overall mean effect for all six studies was small $(d=.098, S E=0.087,95 \% C I[-0.073,0.269], p=.263)$. However, in Study 1 (Martiny et al., 2014a), we found a medium-sized stereotype threat effect for Turkish-origin migrants in the mathematical domain of $d=0.461(S E=0.234,95 \% C I[0.002,0.920], p=.049)$ according to the classification of Cohen (1988). All other studies yielded very small to small effect sizes (see Figure 1). The heterogeneity test was not significant $(Q(5)=3.646, p=.601$ ), which indicated that the effect sizes in our sample did not vary significantly between studies. However, this result should be interpreted with caution because the number of studies included in the metaanalysis is rather small: statistical non-significance could be due to low test power (Higgins et al., 2003).

Hypothesis II: Overall mean effect for moderated stereotype threat effects. To calculate the overall mean effect for the studies investigating moderated stereotype threat effects, we included Study 4 


\begin{tabular}{|c|c|c|c|c|c|c|c|c|c|}
\hline \multirow[t]{8}{*}{$\underline{\text { Model }}$} & Study name & \multicolumn{5}{|c|}{$\underline{\text { Statistics for each study }}$} & \multicolumn{3}{|c|}{$\underline{\text { Std diff in means and } 95 \% \mathrm{CI}}$} \\
\hline & & $\begin{array}{l}\text { Std diff } \\
\text { in means }\end{array}$ & $\begin{array}{c}\text { Standard } \\
\text { error }\end{array}$ & $\begin{array}{c}\text { Lower } \\
\text { limit }\end{array}$ & $\begin{array}{c}\text { Upper } \\
\text { limit }\end{array}$ & p-Value & & & \\
\hline & Study 1 - Martiny, Mok, Deaux et al., 2014 & 0.461 & 0.234 & 0.002 & 0.920 & 0.049 & & & \\
\hline & Study 2 - Mok et al. (2014) & 0.166 & 0.226 & -0.276 & 0.609 & 0.462 & & & \\
\hline & Study 3 - Martiny, Mok, Froehlich et al., 2014 & -0.084 & 0.209 & -0.493 & 0.325 & 0.687 & & & \\
\hline & Study 4 - Froehlich et al. (2016) & 0.041 & 0.178 & -0.308 & 0.391 & 0.818 & & & \\
\hline & Study 5 - Frochlich et al. (2016) & -0.038 & 0.255 & -0.537 & 0.461 & 0.881 & & & \\
\hline & Study 6 - Mok et al. (2017) & 0.101 & 0.206 & -0.303 & 0.506 & 0.623 & & & \\
\hline Random & & 0.098 & 0.087 & -0.073 & 0.269 & 0.263 & & & \\
\hline & & & & & & & -1.20 & -0.60 & 1.20 \\
\hline
\end{tabular}

Figure I. Forest plot of mean effect sizes of all studies.

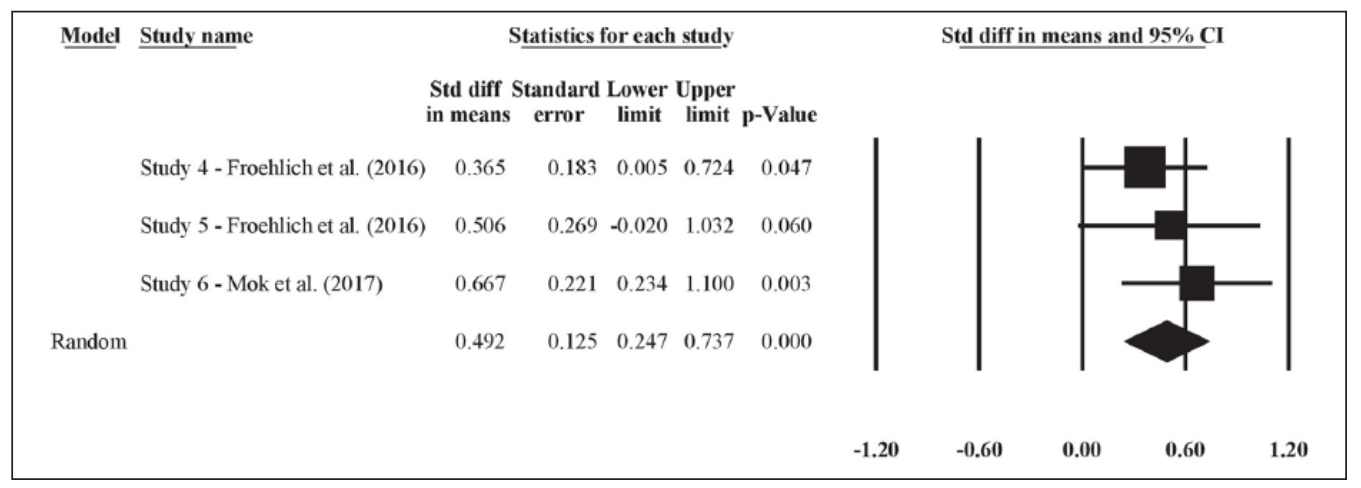

Figure 2. Forest plot of mean effect sizes of studies with moderated stereotype threat effects.

and Study 5 (Froehlich et al., 2016) as well as Study 6 (Mok et al., 2017). We found an overall mean effect of medium size $(d=0.492, S E=0.125, C I[0.737,0.247], p<.001)$, and the heterogeneity test for this subsample was also non-significant $(Q(2)=1.126, p=.57)$. All moderated stereotype threat effect studies showed small to medium effect sizes ( $d$ ranging from .365 to .667; see Figure 2).

\section{Discussion}

Turkish-origin migrants underperform compared to Germans in the educational system, and previous research showed that these performance differences are not fully explained by variables related to students' economic and socio-cultural background (e.g. Autorengruppe Bildungsberichterstattung, 2016). Based on social-psychological research showing widespread negative competence stereotypes about Turkish-origin migrants in Germany (Froehlich et al., 2016), we investigated whether stereotype threat (e.g. Inzlicht and Schmader, 2012) contributes to the explanation of performance differences between Germans and Turkish-origin migrants, focusing on six experimental studies done with 9 th/10th-grade high school students. Here we take stock of the cumulative research evidence when a common paradigm is used. We 
investigated whether the study results showed stereotype threat effects (i.e. lower performance of Turkish-origin migrants after stereotype activation compared to a control condition; Hypothesis I), and whether Turkish-origin migrants' susceptibility to stereotype threat is explained by two newly proposed moderator variables related to the cultural orientation of collectivism (i.e. theory of intelligence and vertical collectivism; Hypothesis II).

\section{Evidence for Hypothesis I: Stereotype threat effects}

We found strong empirical support for stereotype threat effects for negatively stereotyped migrants in Europe and first evidence pointing in the direction of stereotype threat effects for Turkish-origin migrants in Germany, thus supporting Hypothesis I. The summary of empirical evidence revealed that the activation of negative stereotypes in test situations can reduce Turkish-origin migrants' performance, but this evidence was somewhat mixed. A meta-analysis of the six project studies showed that the overall effect size was for the most part directionally consistent, but small and nonsignificant. Further, effect sizes did not significantly vary between studies, which might be explained by the low number of studies included in the meta-analysis and the corresponding low test power (Higgins et al., 2003).

Meta-analyses investigating stereotype threat effects for migrants and minorities in different countries and cognitive domains generally found small to medium effect sizes (e.g. Appel et al., 2015; Nadler and Clark, 2011; Nguyen and Ryan, 2008; Walton and Spencer, 2009). Nguyen and Ryan (2008), for example, investigated stereotype threat effects for women and minorities in a sample of 116 studies and showed an overall effect size of $d=.29$, which was slightly higher when only the studies with an ethnicity-based stereotype were considered $(d=.32)$. Appel et al. (2015) investigated stereotype threat effects for various migrant groups in Europe and the United States in a sample of 19 studies (also including Studies 1 and 4 from the current review) and yielded a medium effect size of $d=.63$ in support of stereotype threat theory. Compared to these small to medium effect sizes, the effect found in the current review $(d=.098)$ is smaller (and non-significant). What might account for this discrepancy in findings? On the one hand, the number of studies in the present meta-analysis was considerably smaller than in the other meta-analyses, because the current analysis is limited to the specific case of Turkish-origin migrants in Germany. Within such a small set of studies, it is more difficult to successfully detect an overall stereotype threat effect. On the other hand, studies have to be designed in very specific ways in order to detect stereotype threat effects. For example, the performance test needs to be reliable and difficult, and test performance needs to depend on working-memory capacity (for a review, see Schmader and Beilock, 2012). In two of the six studies included in the current review (Studies 2 and 3) we were apparently not successful in creating a performance measure that was reliable enough to produce stereotype threat effects, reflected by low internal consistencies. In such a small set of studies as in the current meta-analysis, those studies that did not successfully establish stereotype threat effects have a high impact on the overall mean effect, which might also explain why the effect did not reach statistical significance. A further explanation is that the studies in the current meta-analysis were conducted in school classes (i.e. real-world environments of learning and performance), whereas many studies included in the previously conducted meta-analyses were conducted in laboratory settings. Outside of the controlled laboratory environment, multiple variables could have added error variance to the effect of stereotype threat on performance.

However, even a small-sized stereotype threat effect can have meaningful consequences for the German educational system. Of the over 2.85 million Turkish-origin migrants living in Germany, 900,000 are below 20 years old and are therefore likely to be in secondary education (Bundeszentrale für politische Bildung, 2016). Some researchers have argued that every 
performance situation can invoke negative competence-related stereotypes and stereotype threat (e.g. Aronson and Dee, 2012). We therefore argue that stereotype threat can hinder Turkish-origin migrants from fulfilling their full academic potential in countless everyday performance and testing situations. Further, it is possible that stereotype threat affects individuals repeatedly over time, thus exacerbating its effect over the course of their education. The experience of chronic stereotype threat can lead to severe consequences beyond performance. For example, Turkish-origin migrants might steadily decrease their identification with the academic domain and as a consequence pursue less ambitious educational goals (e.g. Woodcock et al., 2012), and feel a lower sense of belonging to the academic domain (Walton and Cohen, 2007), both of which increase the likelihood of withdrawal from education. Stereotype threat can also reduce social approach motivation (Martiny and Nikitin, in press) and might thereby negatively influence friendships that Turkish-origin migrants have with their classmates. The ongoing threat and pressure could even decrease their well-being and health (e.g. Blascovich et al., 2001; Guendelman, Cheryan, and Monin, 2011; Inzlicht and Kang, 2010). For these reasons, we argue that the overall stereotype threat effect for Turkish-origin migrants found in our studies is small, but nonetheless likely to have an impact in the German educational context.

Further, results showed that in addition to performance reduction, stereotype threat can lead to further consequences when members of the negatively stereotyped group try to restore their positive social identity (Tajfel and Turner, 1986): Turkish-origin students showed different strategies for coping with stereotype threat. They identified more strongly with their ethnic group and believed less in the meta-stereotype about ethnic performance differences (Study 1), but also showed preferences for individual mobility (i.e. being motivated to temporarily leave the negatively stereotyped group in order to join the higher-status group of Germans in a performance situation; Study 6). Thus, depending on the context, Turkish-origin students might react differently to stereotype threat: they might increase their identification with their ethnic group and try to distance themselves (and their group) from the negative stereotype. However, in performance situations in which individual mobility is possible, they might prefer to leave their ethnic group in order to join the higher-status outgroup of Germans. Further research should investigate the conditions under which both coping strategies are used by Turkish-origin migrants under stereotype threat.

\section{Hypothesis II: Moderators of stereotype threat}

Although the current meta-analysis did not show heterogeneity of effect sizes, previous research has emphasized that individuals vary in their susceptibility to stereotype threat (e.g. Nguyen and Ryan, 2008). Therefore, and based on theoretical considerations, we proposed two new moderator variables to explain the extent of Turkish-origin migrants' performance reduction after the activation of negative stereotypes. We found evidence in three studies (Studies 4-6) that the endorsement of an entity theory of intelligence and vertical collectivism predict a more pronounced performance decrease under stereotype threat for Turkish-origin migrants. These moderator variables explained the extent of stereotype threat effects with a mean effect size of $d=.49$, which can be considered a medium effect (Cohen, 1988). Consequently, we were able to shed further light on who is affected by stereotype threat and to what extent. Stereotype threat does not affect all members of the negatively stereotyped group equally, and some individuals have a demonstrably stronger reaction to the threat to their social identity than do others (e.g. Aronson and Dee, 2012). Both the belief that one's intelligence is fixed and the cultural orientation of vertical collectivism intensify stereotype threat effects for Turkish-origin migrants in Germany. Both variables predict the extent to which Turkish-origin migrants see the activation of a negative stereotype in performance situations as a threat to their social identity (Steele et al., 2002). Because negative stereotypes imply that 
Turkish-origin migrants' ability is lower than that of Germans, those Turkish-origin migrants who think that their ability is fixed and unchangeable might worry that they will have difficulties in the performance situation. In their eyes this would indicate that their ability is not high enough to be successful on the task - an outcome that entity theorists experience as failure and as an indication that they are not smart enough, which they think they cannot change (e.g. Dweck, 2006). Furthermore, as Turkish-origin migrants value relatedness and connection to their ingroup members, they internalize the high performance expectations by their family members (Verkuyten et al., 2001). When stereotypes imply that Turkish-origin migrants have low ability, they might perceive it as particularly difficult to fulfill their ingroup members' high performance expectations despite their own high achievement motivation. Thus, Turkish-origin migrants highly endorsing vertical collectivism are strongly affected by stereotype threat. In sum, both newly identified moderator variables predict the degree to which Turkish-origin migrants experience negative stereotypes as a threat to their social identity.

\section{Limitations}

The database reported here, based on six experimental studies with a total of 981 students, is extensive for experimental studies, but is still small for a meta-analysis, and the database needs to be expanded. Further, the current sample of studies is too small to investigate effect sizes based on methodological or contextual moderator variables as Appel et al. (2015) did in their meta-analysis on stereotype threat effects for migrants in general. It would be interesting and relevant to investigate whether effect sizes differ depending on school type (i.e. lower, middle, and higher track), performance domain (i.e. mathematical or verbal performance), or the type of stereotype activation manipulation (i.e. blatant or subtle manipulation). These investigations were not possible with the existing set of studies. Another limitation of the current review is that the studies were conducted with 9th/10th grade high-school students only. Future studies should investigate whether stereotype threat effects for Turkish-origin migrants also occur for students of different age groups to determine the age group in which interventions against stereotype threat could be most effective.

Other research has shown that stereotype threat can have negative consequences over and above test performance. For example, it can increase negative emotions (e.g. Adams et al., 2006), decrease self-confidence (e.g. Koch, Müller, and Sieverding, 2008; Muzzatti and Agnoli, 2007) as well as identification with the domain (e.g. Woodcock et al., 2012) or the group (e.g. Pronin, Steele, and Ross, 2004). It can also decrease task motivation (e.g. Smith, Sansone, and White, 2007), social motivation (e.g. Martiny and Nikitin, in press) and sense of belonging (e.g. Walton and Cohen, 2007) and have a negative impact on health and well-being (e.g. Blascovich et al., 2001; Guendelman et al., 2011; Inzlicht and Kang, 2010). Therefore, future studies might investigate the extent to which stereotype threat has consequences for Turkish-origin migrants beyond their immediate performance.

\section{Practical implications}

Results showed that negative competence-related stereotypes about Turkish-origin migrants are endorsed by preservice teachers and the activation of those stereotypes in test situations can hinder Turkish-origin migrants from fulfilling their intellectual potential. These social-psychological variables provide a new explanation for ethnic performance differences in the German educational system and can thus make a unique contribution to the unexplained performance differences between Turkish-origin and German students. Further, the experimental approach shows that the achievement gap does not depend on ability differences between Turkish-origin migrants and 
Germans, but rather that Turkish-origin migrants underperform only when negative stereotypes are activated. Put differently, ethnic performance differences are dependent on the performance situation - in turn, the achievement gap would be reduced when ethnic group membership and the corresponding stereotypes were not salient in performance situations. Including moderator variables that explain Turkish-origin migrants' susceptibility to stereotype threat also shows that not all individuals experience stereotype threat to the same extent. Instead, Turkish-origin students vary in their perception of the performance situation as a threat to their social identity. These results open up pathways to interventions designed to increase equal opportunities for all ethnic groups in the German educational system.

One approach is to develop interventions that create learning and testing situations in which negative group-related stereotypes do not hinder performance (i.e. identity-safe testing environments, that is, testing environments in which social identity is not threatened; Spencer et al., 2016). For example, teachers as well as authors of testing materials could reduce the likelihood that students are reminded of their membership in negatively stereotyped groups (e.g. instead of asking students to indicate their gender, ethnicity, or native language before performance tests, they should always assess this information after the test). Furthermore, preservice teachers as well as certified teachers should receive training about stereotype threat. If teachers endorse negative competence-related stereotypes about migrant students, these stereotypes can shape their attitudes and behavior. Stereotypes can even be activated automatically and unconsciously and subsequently influence behavior (e.g. Bargh, Chen, and Burrows, 1996), leading to inadvertent and unconscious discriminatory behavior by teachers against students (e.g. having low performance expectations, not calling on Turkish-origin students when difficult questions are asked, or providing dependency-oriented help instead of autonomy-oriented help). When (preservice) teachers reflect on their own stereotypes during their training, they might develop conscious and controlled strategies to recognize and counteract automatic stereotype activation. In doing so, they may be able to develop strategies that control the influence of stereotypes on performance expectations and behavior toward Turkish-origin students (for practical recommendations, see Mok, Froehlich, and Scholz, 2015). One important aspect of teacher training is to inform teachers that everyone has stereotypes, because stereotypes help to structure the perceived social environment (e.g. Klauer, 2008). Thus, the goal of teacher trainings is not that teachers "get rid" of their stereotypes, but that they are aware of them and try to limit their influence on their perceptions of and behavior toward Turkish-origin students in classrooms.

Another approach is to develop interventions directed at the students with the goal of decreasing their susceptibility to stereotype threat. In this case, the aim is to reduce the stereotype-induced pressure that students experience in performance situations rather than to eliminate the stereotypes themselves. These interventions would attempt to change students' views that their social identities are threatened by the expressed stereotypes (i.e. coping interventions, Spencer et al., 2016). For example, interventions that teach students to endorse an incremental theory of intelligence (i.e. the notion that one can expand one's intelligence and ability by learning and effort; e.g. Dweck, 2006) could increase students' resilience to the activation of negative stereotypes. Typically, these interventions instruct students that "the brain is like a muscle - it changes as you train it," which conveys that they can increase their ability by learning and effort. This message motivates students and alleviates their concern about not being smart enough in performance situations (e.g. Blackwell, Trzesniewski, and Dweck, 2007; Martinez and Mendoza-Denton, 2011; Yeager et al., 2016, but see recent meta-analysis by Sisk et al., 2018).

Another group of interventions aims at increasing negatively stereotyped students' feelings of belongingness with the academic environment (e.g. Walton and Cohen, 2007, 2011). Although a recent social belonging intervention with migrant students in Austria did not yield significant intervention effects, the initial levels of belongingness of migrant students (who were actually in the majority in their classrooms) were already relatively high and perhaps could not be further increased 
by the intervention (Weber, Kronberger, and Appel, 2018). Further research to adapt interventions developed in the US-American educational context to the European and German context is needed.

A further group of interventions directed at students relies on affirmation of the self or an important value of the self. With this approach, before taking a test, students are asked to indicate a characteristic of themselves that they value the most (e.g. sense of humor, creativity, social skills) and reflect on why this value is important to them. This activity affirms their self-integrity, which would otherwise be threatened by the negative stereotypes. Consequently, students perceive the subsequent performance situation as less threatening (e.g. Martens et al., 2006; Sherman et al., 2013). However, a recent study conducting a values affirmation intervention with migrant students in the Netherlands was not able to show beneficial effects of the intervention on migrants' performance (de Jong et al., 2016). The authors suggest that their intervention might have failed to produce the expected effects because the values affirmation exercise was originally developed for a different population, that is, African-American students in the United States, and did not generalize to predominantly Muslim migrant students in the Netherlands. More specifically, the Muslim students frequently chose religious and communal values to reflect on, which might have increased instead of attenuated stereotype threat, because of the common link between religious and ethnic identity in this group (Verkuyten and Yildiz, 2007). As long as it is not yet feasible to create identity-safe testing sessions in which stereotypes are never salient, the more promising strategy for reducing the ethnic achievement gap is to reduce students' susceptibility to stereotype threat by interventions that teach them ways to cope with the social identity threats (Spencer et al., 2016).

\section{Conclusion}

The academic performance of Turkish-origin migrants is partly shaped by their ethnic group membership - a category that is negatively evaluated in German society. The current review and metaanalysis highlights the complex interplay of group membership, negative stereotypes, social identity, and academic performance. The social-psychological approach based on stereotype threat theory opens up new pathways to interventions that can reduce ethnic inequalities in the German educational system. Teachers are encouraged to create identity-safe testing environments and reflect on their own stereotypes about (Turkish-origin) migrants.

\section{Declaration of conflicting interest}

The authors declare that there is no conflict of interest.

\section{Funding}

This research was funded by the Federal Ministry of Education and Research (BMBF); grant number: 01JC1104.

\section{Note}

1. Project title: "Stereotype Threat als Ursache niedriger Leistungen von Schülerinnen und Schülern mit Migrationshintergrund im deutschen Bildungssystem"; data are available upon request from the IQB (Institut für Qualitätssicherung im Bildungswesen; project webpage: https://www.iqb.hu-berlin.de/fdz/ studies/Stereotype_Threat).

\section{References}

Adams G, Garcia DM, Purdie-Vaughns V, et al. (2006) The detrimental effects of a suggestion of sexism in an instruction situation. Journal of Experimental Social Psychology 42(5): 602-615. 
Appel M, Weber S and Kronberger N (2015) The influence of stereotype threat on immigrants: Review and meta-analysis. Frontiers in Psychology, 6: 900.

Aronson J and Dee T (2012) Stereotype threat in the real world. In: Inzlicht M and Schmader T (eds) Stereotype Threat: Theory, Process, and Application. New York: Oxford University Press, pp.264-279.

Asbrock F (2010) Stereotypes of social groups in Germany in terms of warmth and competence. Social Psychology 41(2): 76-81.

Autorengruppe Bildungsberichterstattung (2016) Bildung in Deutschland 2016: Ein indikatorengestützter Bericht Mit einer Analyse zu Bildung und Migration [Education in Germany 2016: An IndicatorSupported Report Including an Analysis of Education and Migration]. Bielefeld: W. Bertelsmann Verlag.

Baier D, Pfeiffer C, Rabold S, et al. (2010) Kinder und Jugendliche in Deutschland: Gewalterfahrungen, Integration, Medienkonsum: Zweiter Bericht zum Gemeinsamen Forschungsprojekt des Bundesministeriums des Inneren und des KFN [Children and Adolescents in Germany: Experiences of Violence, Integration, and Media Use]. Forschungsbericht N. 109. [Research Report No 109]. Hannover: Kriminologisches Forschungsinstitut Niedersachsen (KFN).

Bargh JA, Chen M and Burrows L (1996) Automaticity of social behavior: Direct effects of trait construct and stereotype activation on action. Journal of Personality and Social Psychology 71(2): 230-244.

Baysu G, Celeste L, Brown R, et al. (2016) Minority adolescents in ethnically diverse schools: Perceptions of equal treatment buffer threat effects. Child Development 87(5): 1352-1366.

Baysu G, Phalet K and Brown R (2011) Dual identity as a two-edged sword: Identity threat and minority school performance. Social Psychology Quarterly 74(2): 121-143.

Blackwell LS, Trzesniewski KH and Dweck CS (2007) Implicit theories of intelligence predict achievement across an adolescent transition: A longitudinal study and an intervention. Child Development 78(1): 246-263.

Blascovich J, Spencer SJ, Quinn D, et al. (2001) African Americans and high blood pressure: The role of stereotype threat. Psychological Science 12(3): 225-229.

Borenstein M, Hedges LV, Higgins JPT, et al. (eds) (2009) Introduction to Meta-Analysis. Chichester: Wiley.

Bundeszentrale für politische Bildung (2016) Die Soziale Situation in Deutschland: Migration: Migrationshintergrund I [The social situation in Germany: Migration. Migation background I]. Available at: http://www.bpb.de/nachschlagen/zahlen-und-fakten/soziale-situation-in-deutschland/61646/migrationshintergrund-i (accessed 13 September 2017).

Cadinu M, Maass A, Lombardo M, et al. (2006) Stereotype threat: The moderating role of locus of control beliefs. European Journal of Social Psychology 36(2): 183-197.

Cohen J (1988) Statistical Power Analysis for the Behavioral Sciences. 2nd ed. Hillsdale, NJ: L. Erlbaum Associates.

Cuddy AJC, Fiske ST and Glick P (2007) The BIAS map: Behaviors from intergroup affect and stereotypes. Journal of Personality and Social Psychology 92(4): 631-648.

De Jong EM, Jellesma FC, Koomen HMY, et al. (2016) A values-affirmation intervention does not benefit negatively stereotyped immigrant students in the Netherlands. Frontiers in Psychology 7: 691.

De Paola M and Brunello G (2016) Education as a tool for the economic integration of migrants. Available at: http://www.eenee.de/dms/EENEE/Analytical_Reports/EENEE_AR27.pdf (accessed 13 September 2017).

Die Beauftragte der Bundesregierung für Migration, Flüchtlinge und Integration (2016) 11. Bericht der Beauftragten der Bundesregierung für Migration, Flüchtlinge und Integration - Teilhabe, Chancengleichheit und Rechtsentwicklung in der Einwanderungsgesellschaft Deutschland [11th report of the Federal Government Commissioner for migration, refugees and integration - participation, equal opportunities and legal development in the immigration society of Germany]. Available at: https:// www.bundesregierung.de/Content/Infomaterial/BPA/IB/11-Lagebericht_09-12-2016.html (accessed 13 September 2017).

Dweck CS (1999) Self-Theories: Their Role in Motivation, Personality, and Development. Philadelphia, PA: Psychology Press.

Dweck CS (2006) Mindset: The New Psychology of Success. New York: Random House.

Dweck CS, Chiu C and Hong Y (1995) Implicit theories and their role in judgments and reactions: A word from two perspectives. Psychological Inquiry 6(4): 267-285. 
Elizaga RA and Markman KD (2008) Peers and performance: How in-group and out-group comparisons moderate stereotype threat effects. Current Psychology 27(4): 290-300.

Ellemers N, Knippenberg A and Wilke H (1990) The influence of permeability of group boundaries and stability of group status on strategies of individual mobility and social change. British Journal of Social Psychology 29(3): 233-246.

Fiske ST, Cuddy AJC, Glick P, et al. (2002) A model of (often mixed) stereotype content: Competence and warmth respectively follow from perceived status and competition. Journal of Personality and Social Psychology 82(6): 878-902.

Froehlich L and Schulte I (2018) Warmth and competence stereotypes about immigrant groups in Germany. Manuscript sumbitted for publication.

Froehlich L, Martiny SE, Deaux K, et al. (2016a) Being smart or getting smarter: Implicit theory of intelligence moderates stereotype threat and stereotype lift effects. British Journal of Social Psychology 55(3): 564-587.

Froehlich L, Martiny SE, Deaux K, et al. (2016b) "It's their responsibility, not ours": Stereotypes about competence and causal attributions for immigrants' academic underperformance. Social Psychology 47(2): $74-86$.

Grant H and Dweck CS (2001) Cross-cultural response to failure: Considering outcome attributions with different goals. In: Salili F, Chiu C-Y and Hong Y-Y (eds) Student Motivation: The Culture and Context of Learning. New York: Kluwer Academic, pp.203-219.

Grant H and Dweck CS (2003) Clarifying achievement goals and their impact. Journal of Personality and Social Psychology 85(3): 541-553.

Guendelman MD, Cheryan S and Monin B (2011) Fitting in but getting fat: Identity threat and dietary choices among U.S. immigrant groups. Psychological Science 22(7): 959-967.

Güngör D, Karasawa M, Boiger M, et al. (2014) Fitting in or sticking together: The prevalence and adaptivity of conformity, relatedness, and autonomy in Japan and Turkey. Journal of Cross-Cultural Psychology 45(9): 1374-1389.

Higgins JPT, Thompson SG, Deeks JJ, et al. (2003) Measuring inconsistency in meta-analyses. BMJ: British Medical Journal 327(7414): 557-560.

Hofstede GH, Hofstede GJ and Minkov M (2010) Cultures and Organizations: Software of the Mind: Intercultural Cooperation and its Importance for Survival. 3rd ed. New York: McGraw-Hill.

Inzlicht M and Kang SK (2010) Stereotype threat spillover: How coping with threats to social identity affects aggression, eating, decision making, and attention. Journal of Personality and Social Psychology 99(3): 467-481.

Inzlicht M and Schmader T (2012) Introduction. In: Inzlicht M and Schmader T (eds) Stereotype Threat: Theory, Process, and Application. New York: Oxford University Press, pp.3-14.

Jetten J, Branscombe NR, Schmitt MT, et al. (2016) Rebels with a cause: Group identification as a response to perceived discrimination from the mainstream. Personality and Social Psychology Bulleti, 27(9): 1204-1213.

Jones BD, Ruff C and Paretti MC (2013) The impact of engineering identification and stereotypes on undergraduate women's achievement and persistence in engineering. Social Psychology of Education 16(3): 471-493.

Kassin SM, Fein S and Markus HR (2011) Social psychology. 7th ed. Belmont, CA: Wadsworth.

Keller J (2007) Stereotype threat in classroom settings: The interactive effect of domain identification, task difficulty and stereotype threat on female students' maths performance. British Journal of Educational Psychology 77(2): 323-338.

Kervyn N, Fiske ST and Yzerbyt V (2015) Forecasting the primary dimension of social perception: Symbolic and realistic threats together predict warmth in the stereotype content model. Social Psychology 46(1): $36-45$.

Klauer KC (2008) Soziale Kategorisierung und Stereotypisierung. In: Petersen L-E (ed) Stereotype, Vorurteile und Soziale Diskriminierung: Theorien, Befunde und Interventionen. 1st ed. Weinheim Basel: Beltz, PVU, pp.23-32.

Klieme E, Artelt C, Hartig J, et al. (eds) (2010) PISA 2009: Bilanz nach einem Jahrzehnt [PISA 2009: Taking Stock After a Decade]. Münster: Waxmann Verlag. 
Koch SC, Müller SM and Sieverding M (2008) Women and computers: Effects of stereotype threat on attribution of failure. Computers and Education 51(4): 1795-1803.

Komarraju M and Cokley KO (2008) Horizontal and vertical dimensions of individualism-collectivism: A comparison of African Americans and European Americans. Cultural Diversity and Ethnic Minority Psychology 14(4): 336-343.

Länderoffene Arbeitsgruppe "Indikatorenentwicklung und Monitoring" (2017) Vierter Bericht zum Integrationsmonitoring der Länder 2013-2015. [Fourth report of the intergration monitoring of the federal states 2013-2015]. Konferenz der für Integration zuständigen Ministerinnnen und Minister/ Senatorinnen und Senatoren der Länder (IntMK). Available at: http://www.integrationsmonitoringlaender.de/sites/default/files/integrationsbericht_2015_endfassung_online.pdf (accessed 11 October 2018).

Lee TL and Fiske ST (2006) Not an outgroup, not yet an ingroup: Immigrants in the stereotype content model. International Journal of Intercultural Relations 30(6): 751-768.

Levy SR, Stroessner SJ and Dweck CS (1998) Stereotype formation and endorsement: The role of implicit theories. Journal of Personality and Social Psychology 74(6): 1421-1436.

Martens A, Johns M, Greenberg J, et al. (2006) Combating stereotype threat: The effect of self-affirmation on women's intellectual performance. Journal of Experimental Social Psychology 42(2): 236-243.

Martinez AG and Mendoza-Denton R (2011) The prospect of plasticity: Malleability views of group differences and their implications for intellectual achievement, mental/behavioral health, and public policy. Social Issues and Policy Review 5(1): 137-159.

Martiny SE and Götz T (2011) Stereotype Threat in Lern- und Leistungssituationen: Theoretische Ansätze, empirische Befunde und praktische Implikationen. In: Dresel M and Lämmle L (eds) Talentförderung Expertiseentwicklung - Leistungsexzellenz: Vol. 9. Motivation, Selbstregulation und Leistungsexzellenz. Münster: LIT, pp.153-177.

Martiny SE and Nikitin J (in press) Social Identity Threat in Interpersonal Relationships: Activating Negative Stereotypes Decreases Social Approach Motivation. Journal of Experimental Psychology: Applied.

Martiny SE, Mok SY, Deaux K, et al. (2014a) Effects of activating negative stereotypes about Turkish-origin students on performance and identity management in German high schools. International Review of Social Psychology 3(Tome 27): 205-225.

Martiny SE, Mok SY, Froehlich L, et al. (2014b) Does a Test Fairness Manipulation Trigger a Stereotype Threat Effect on Verbal Performance of Turkish-Origin Students in Germany? Unpublished manuscript. University of Konstanz, Germany.

Mok SY, Froehlich L and Scholz C (2015) Leistungsminderung durch negative Stereotype im Schulkontext [Performance reduction due to negative stereotypes in school]. Lehren and Lernen 41(1): 28-31.

Mok SY, Martiny SE, Froehlich L, et al. (2014) Do Turkish-Origin Students in Germany Suffer From Stereotype Threat Effects in Math When a Test is Labeled as Diagnostic for Students' Intelligence? Unpublished manuscript.

Mok SY, Martiny SE, Gleibs IH, et al. (2016) The relationship between ethnic classroom composition and Turkish-origin and German students' reading performance and sense of belonging. Frontiers in Psychology 7(1071): 366.

Mok SY, Martiny SE, Gleibs IH, et al. (2017) The interaction of vertical collectivism and stereotype activation on the performance of Turkish-origin high school students. Learning and Individual Differences 56: $76-84$.

Muzzatti B and Agnoli F (2007) Gender and mathematics: Attitudes and stereotype threat susceptibility in Italian children. Developmental Psychology 43(3): 747-759.

Nadler JT and Clark MH (2011) Stereotype threat: A meta-analysis comparing African Americans to Hispanic Americans. Journal of Applied Social Psychology 41(4): 872-890.

Nguyen H-HD and Ryan AM (2008) Does stereotype threat affect test performance of minorities and women? A meta-analysis of experimental evidence. Journal of Applied Psychology 93(6): 1314-1334.

Pennington CR, Heim D, Levy AR, et al. (2016) Twenty years of stereotype threat research: A review of psychological mediators. PloS One 11(1): e0146487. 
Phalet K and Claeys W (1993) A comparative study of Turkish and Belgian youth. Journal of Cross-Cultural Psychology 24(3): 319-343.

Prenzel M(2013) PISA 2012: Fortschritte und Herausforderungen in Deutschland. [PISA 2012: Advancements and challenges in Germany]. Münster: Waxmann.

Pronin E, Steel CM and Ross L (2004) Identity bifurcation in response to stereotype threat: Women and mathematics. Journal of Experimental Social Psychology 40(2): 152-168.

Rauch D, Mang J, Härtig H, et al. (2016) Naturwissenschaftliche Kompetenz von Schülerinnen und Schülern mit Zuwanderungshintergrund [Science competencies of students with migration background]. In: Reiss K, Sälzer C, Schiepe-Tiska A, et al. (eds) PISA 2015: Eine Studie Zwischen Kontinuität und Innovation. Münster: Waxmann, pp.317-348.

Rydell RJ and Boucher KL (2010) Capitalizing on multiple social identities to prevent stereotype threat: The moderating role of self-esteem. Personality and Social Psychology Bulletin 36(2): 239-250.

Sander A, Ohle A, McElvany N, et al. (2018) Stereotypenbedrohung als Ursache für geringeren Wortschatzzuwachs bei Grundschulkindern mit Migrationshintergrund [Stereotype threat as a cause of lower vocabulary increase for elementary school students with migration background]. Zeitschrift Für Erziehungswissenschaft 21(1): 177-197.

Schmader T (2002) Gender identification moderates stereotype threat effects on women's math performance. Journal of Experimental Social Psychology 38(2): 194-201.

Schmader T and Beilock SL (2012) An integration of processes that underlie stereotype threat. In: Inzlicht M and Schmader T (eds) Stereotype Threat: Theory, Process, and Application. New York: Oxford University Press, pp.34-50.

Schmader T, Johns M and Barquissau M (2004) The costs of accepting gender differences: The role of stereotype endorsement in women's experience in the math domain. Sex Roles 50(11-12): 835-850.

Schmader T, Johns M and Forbes C (2008) An integrated process model of stereotype threat effects on performance. Psychological Review 115(2): 336-356.

Schmid M (ed) (2014) Italienische Migration nach Deutschland [Italian Migration to Germany]. Wiesbaden: Springer Fachmedien Wiesbaden.

Schofield JW and Alexander K (2012) Stereotype threat, Erwartungseffekte und organisatorische Differenzierung: Schulische Leistungsbarrieren und Ansätze zu ihrer Überwindung. In: Fürstenau S and Gomolla M (eds) Migration und Schulischer Wandel: Leistungsbeurteilung. Dordrecht: Springer, pp.65-88.

Schwippert K, Wendt H and Tarelli I (2012) Lesekompetenzen von Schülerinnen und Schülern mit Migrationshintergrund [Reading competencies of students with migration background]. In: Bos W (ed) IGLU 2011: Lesekompetenzen von Grundschulkindern in Deutschland im Internationalen Vergleich. Münster: Waxmann pp.191-208.

Sherman DK, Hartson KA, Binning KR, et al. (2013) Deflecting the trajectory and changing the narrative: How self-affirmation affects academic performance and motivation under identity threat. Journal of Personality and Social Psychology 104(4): 591-618.

Shih M, Pittinsky TL and Trahan A (2006) Domain-specific effects of stereotypes on performance. Self and Identity 5(1): 1-14.

Singelis TM, Triandis HC, Bhawuk DPS, et al. (1995) Horizontal and vertical dimensions of individualism and collectivism: A theoretical and measurement refinement. Cross-Cultural Research 29(3): $240-275$.

Sisk VF, Burgoyne AP, Sun J, et al. (2018) To what extent and under which circumstances are growth mind-sets important to academic achievement? Two meta-analyses. Psychological Science 29(4): 549-571.

Smith JL, Sansone C and White PH (2007) The stereotyped task engagement process: The role of interest and achievement motivation. Journal of Educational Psychology 99(1): 99-114.

Spencer SJ, Logel C and Davies PG (2016) Stereotype threat. Annual Review of Psychology 67: 415-437.

Spencer SJ, Steele CM and Quinn DM (1999) Stereotype threat and women's math performance. Journal of Experimental Social Psychology 35(1): 4-28. 
Stanat P, Rauch D and Segeritz M (2010) Schülerinnen und Schüler mit Migrationshintergrund [Students with migration background]. In: Klieme E, Artelt C, Hartig J, et al. (eds) PISA 2009: Bilanz Nach einem Jahrzehnt [PISA 2009: Taking Stock After a Decade]. Münster: Waxmann Verlag, pp.200-230.

Statistisches Bundesamt (2016) Datenreport 2016: Ein Sozialbericht für die Bundesrepublik Deutschland [Data Report 2016: A Social Report for the Federal Republic of Germany]. Bonn: Reihe Zeitbilder.

Statistisches Bundesamt (2017) Bevölkerung und Erwerbstätigkeit: Bevölkerung mit Migrationshintergrund: Ergebnisse des Mikrozensus 2016. [Population and Labor: Population With Migration Background. Results of the Micro Census 2016]. Fachserie 1 Reihe 2.2. Wiesbaden: Statistisches Bundesamt.

Steele CM (1997) A threat in the air: How stereotypes shape intellectual identity and performance. American Psychologist 52(6): 613-629.

Steele CM and Aronson J (1995) Stereotype threat and the intellectual test performance of African Americans. Journal of Personality and Social Psychology 69(5): 797-811.

Steele CM, Spencer SJ and Aronson J (2002) Contending with group image: The psychology of stereotype and social identity threat. In: Zanna MP (ed) Advances in Experimental Social Psychology, Vol. 34. San Diego, CA: Academic Press, pp.379-440.

Strasser J (2012) Kulturelle Stereotype und ihre Bedeutung für das Verstehen in Schule und Unterricht [Cultural stereotypes and their meaning for understanding in education and instruction]. In: Wiater W and Manschke D (eds) Verstehen und Kultur. Wiesbaden: VS Verlag für Sozialwissenschaften, pp.191-215.

Tajfel H and Turner JC (1979) An integrative theory of intergroup conflict. In: Austin WG and Worchel S (eds) The Social Psychology of Intergroup Relations. Monterey, CA: Brooks/Cole, pp.33-47.

Tajfel H and Turner JC (1986) The social identity theory of intergroup behavior. In:Worchel S and Austin WG (eds) Psychology of Intergroup Relations. Chicago: Nelson-Hall, pp.7-24.

Varnum MEW, Grossmann I, Kitayama S, et al. (2010) The origin of cultural differences in cognition: Evidence for the social orientation hypothesis. Current Directions in Psychological Science 19(1): 9-13.

Verkuyten M and Yildiz AA (2007) National (dis)identification and ethnic and religious identity: A study among Turkish-Dutch muslims. Personality and Social Psychology Bulletin 33(10): 1448-1462. 04276

Verkuyten M, Thijs J and Canatan K (2001) Achievement motivation and academic performance among Turkish early and young adolescents in the Netherlands. Genetic, Social, and General Psychology Monographs 127(4): 378-408.

Walton GM and Cohen GL (2003) Stereotype lift. Journal of Experimental Social Psychology 39(5): 456-467.

Walton GM and Cohen GL (2007) A question of belonging: Race, social fit, and achievement. Journal of Personality and Social Psychology 92(1): 82-96.

Walton GM and Cohen GL (2011) A brief social-belonging intervention improves academic and health outcomes of minority students. Science 331(6023): 1447-1451.

Walton GM and Spencer SJ (2009) Latent ability: Grades and test scores systematically underestimate the intellectual ability of negatively stereotyped students. Psychological Science 20(9): 1132-1139.

Weber S, Appel M and Kronberger N (2015) Stereotype threat and the cognitive performance of adolescent immigrants: The role of cultural identity strength. Contemporary Educational Psychology 42: 71-81.

Weber S, Kronberger N and Appel M (2018) Immigrant students' educational trajectories: The influence of cultural identity and stereotype threat. Self and Identity 17(2): 211-235.

Wendt H, Schwippert K and Stubbe TC (2016) Mathematische und naturwissenschaftliche Kompetenzen von Schülerinnen und Schülern mit Migrationshintergrund [Math and science competencies of students with migration background]. In: Wendt H, Bos W, Selter C, et al. (eds) TIMSS 2015: Mathematische und Naturwissenschaftliche Kompetenzen von Grundschulkindern in Deutschland im Internationalen Vergleich. Münster and New York: Waxmann, pp.317-331.

Whitley BE and Kite ME (2016) Psychology of Prejudice and Discrimination. 3rd ed. New York: Routledge. Woodcock A, Hernandez PR, Estrada M, et al. (2012) The consequences of chronic stereotype threat: Domain disidentification and abandonment. Journal of Personality and Social Psychology 103(4): 635-646.

Yeager DS, Walton GM, Brady ST, et al. (2016) Teaching a lay theory before college narrows achievement gaps at scale. Proceedings of the National Academy of Sciences of the United States of America 113(24): E3341-E3348. 


\section{Author biographies}

Laura Froehlich is a Post-Doctoral Researcher in the Department of Social Psychology at the FernUniversität in Hagen, Germany. She received her PhD in Psychology from the University of Konstanz in 2015. Her research interests are stereotypes about gender and ethnicity, self \& identity processes for immigrants as well as cross-cultural approaches to social psychology.

Sog Yee Mok is a Post-Doctoral Researcher at the Institute for Educational Science at the University of Zurich, Switzerland. She received her $\mathrm{PhD}$ in Empirical Educational Research from the University of Konstanz in 2015. Her research interests are stereotype threat and identity processes for students with migration background, as well as evidence-based teacher training and teacher-student-interactions.

Sarah E. Martiny is a Full Professor of Social and Community Psychology at UiT The Arctic University of Norway in Tromsø, Norway. She received her PhD from the University of Jena in 2008 and worked as a PostDoctoral Researcher with Kay Deaux at New York University in 2009. She was an Assistant Professor in Empirical Educational Research at the University of Konstanz from 2010 to 2014. Her research interests are in the area of social identity and intergroup relations including topics such as migration, gender, and social inequality.

Kay Deaux is a Distinguished Professor Emerita at the Graduate Center of the City University of New York and a Visiting Scholar at New York University, USA. She received the Distinguished Scholar Award from the Society of Personality and Social Psychology in 2016. She has a long history in research on stereotypes, discrimination, and social identity in the areas of gender and immigration. 